\title{
RECONCILING BUBBLE NUCLEATION IN EXPLOSIVE ERUPTIONS WITH GEOSPEEDOMETERS
}

\author{
Sahand Hajimirza ${ }^{1 *}$, Helge M. Gonnermann ${ }^{1}$, and James E. Gardner ${ }^{2}$ \\ ${ }^{1}$ Department of Earth, Environmental and Planetary Sciences, Rice University, Houston, TX, USA \\ ${ }^{2}$ Jackson School of Geosciences, University of Texas at Austin, Austin, TX, USA
}

\begin{abstract}
Magma from Plinian volcanic eruptions contains an extraordinarily large numbers of bubbles. Nucleation of those bubbles occurs because pressure decreases as magma rises to the surface. As a consequence dissolved magmatic volatiles, such as water, become supersaturated and cause bubbles to nucleate. At the same time diffusion of volatiles into existing bubbles reduces supersaturation, resulting in a dynamical feedback between rates of nucleation due to magma decompression and volatile diffusion. Because nucleation rate increases with supersaturation, bubble number density (BND) provides a proxy record of decompression rate and, hence, the intensity of eruption dynamics. Using numerical modeling of bubble nucleation here we reconcile a long-standing discrepancy in decompression rate estimated from BND and independent geospeedometers. We demonstrate that BND provides a record of the time-averaged decompression rate that is consistent with independent geospeedometers, if bubble nucleation is heterogeneous and facilitated by magnetite crystals.
\end{abstract}

\section{INTRODUCTION}

Plinian eruptions are among Earth's most explosive volcanic events and are typically associated with magmas of high silica content [1]. In the past $100 \mathrm{kyr}$, over 500 Plinian silicic eruptions with Volcanic Explosivity Index (VEI) of 4 or greater have occurred globally [2] (Figure 1a). These eruptions have considerable destructive power and present extensive risks, both locally (e.g. pyroclastic density current) and globally (e.g. atmospheric ash and aerosol dispersal). The destructive potential of such eruptions derives from numerous bubbles that nucleate and grow during magma ascent $[3,4]$. These bubbles contain a highly compressible fluid mixture of exsolved magmatic volatiles, predominantly $\mathrm{H}_{2} \mathrm{O}^{[}[5]^{]}$. Bubble overpressure, relative to the surrounding melt, provides the potential energy for magma fragmentation, which results in explosive eruptions [6] The development of overpressure in bubbles is thought to depend on the rate at which magma decompresses during ascent $[7,8]$. Because eruptive processes are inaccessible to direct observation, understanding explosive volcanism is contingent upon reconstructing governing processes and their controlling parameters from indirect observations. The number density of bubbles, preserved in erupted pyroclasts, is such an independent observation and of critical importance to elucidating the dynamical feedback between magma decompression, $\mathrm{H}_{2} \mathrm{O}$ exsolution, and explosive magma fragmentation.

Bubble nucleation rate and the resultant bubble number density are governed by the feedback between $\mathrm{H}_{2} \mathrm{O}$ exsolution and magma decompression [4]. The latter is a consequence of the combined decrease in static pressure and pressure loss from viscous resistance to flow, as magma rises toward the surface [6]. Consequently, decompression rate depends dynamically on magma discharge rate, conduit dimensions, and magma viscosity which increases as $\mathrm{H}_{2} \mathrm{O}$ exsolves into bubbles by diffusion [9]. The efficiency of diffusion, in turn, is rate limited by the number density of bubbles, such that slow diffusion kinetics facilitates large supersaturations and high rates of bubble nucleation [4]. Bubble number density provides a record of this feedback. Reconstruction of these processes and reliable estimation of magma decompression rate require quantitative models of bubble nucleation that are calibrated with experiments.

Bubble number densities preserved in pyroclasts from Plinian silicic eruptions span a narrow range of $10^{15 \pm 1} \mathrm{~m}^{-3}$ despite more than $3 \mathrm{wt} \%$ variation in pre-eruptive $\mathrm{H}_{2} \mathrm{O}$ concentrations (Figure 1b). The observed bubble number densities are compared with experimental results of homogeneous nucleation in Figure 1b. The data are presented in terms of the potential maximum supersaturation pressure. In case of experiments it is the difference between the $\mathrm{H}_{2} \mathrm{O}$ saturation pressure and the final pressure, whereas for eruptions it is the difference between saturation pressure and atmospheric pressure. Homogeneous nucleation typically initiates at supersaturation pressures of $\approx 110 \mathrm{MPa}$ [e.g. 10]. Bubble number density increases with supersaturation pressure, and it reaches the range of bubble number density observed in pyroclasts at supersaturation pressures of $>150 \mathrm{MPa}$. Such high pressures, however, are greater than the potential maximum supersaturation pressure for most eruptions [11]. Moreover, the conventional estimates of decompression rate based on homogeneous nucleation are unrealistically high $\left(\sim 100 \mathrm{MPa} \mathrm{s}^{-1}\right)$, do not correlate with magma discharge rate, and are substantially greater than estimates from independent geospeedometers, which are $\leq 1 \mathrm{MPa} \mathrm{s}^{-1}$ (Figure 1c). To resolve these discrepancies, Shea [11] hypothesized that bubble nucleation is perhaps heterogeneous facilitated by abundant pre-existing crystals. The heterogeneous nucleation hypothesis, however, does not close the gap between decompression rate estimates from BND and independent geospeedometers.

The purpose of this study is to reconcile observed bubble number densities in Plinian silicic eruptions with independent geospeedometers. We integrate Hajimirza et al. [30]'s bubble nucleation model, obtained by calibrating classical nucleation 

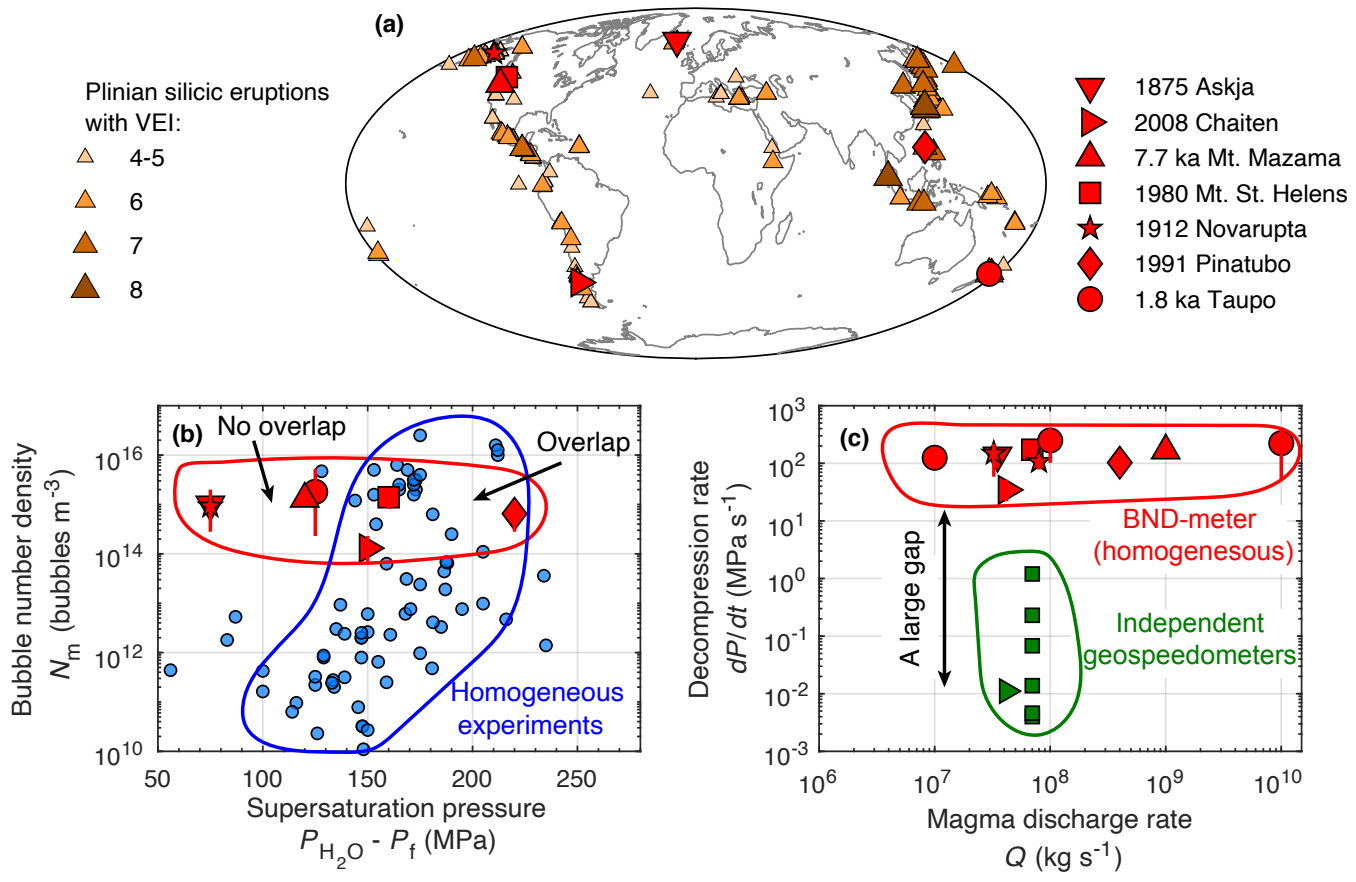

Figure 1: Plinian silicic eruptions, their observed bubble number densities and their inferred decompression rates. (a) Spatial distribution of Plinian (Volcanic Explosivity Index $\geq 4$ ) silicic eruptions over the past $100 \mathrm{kyr}$, based on Crosweller et al. [2]. Red symbols are eruptions for which bubble number density and $\mathrm{H}_{2} \mathrm{O}$ saturation pressure are documented. They are: 1875 Askja [12, 13]; 2008 Chaiten [14, 15]; 7.7 ka Mount Mazama [16, 17]; 1980 Mount St. Helens (MSH) [18, 19, 20 ]; 1912 Novarupta [21, 22]; 1991 Pinatubo [23, 24]; 1.8 ka Taupo [25] eruptions. (b) Bubble number density versus the maximum potential $\mathrm{H}_{2} \mathrm{O}$ supersaturation pressure for eruptions (red symbols) and for homogeneous nucleation experiments (blue symbols) $[26,27,28,29,30,31,10,32,33,34]$. Only experiments with supersaturation pressure of $\geq 150 \mathrm{MPa}$ overlap with eruptions. (c) Decompression rate values estimated from observed bubble number density and homogeneous nucleation [35]. There is a large gap between these estimates and those calculated by independent geospeedometers for the same eruptions [15, 36, 37, 38, 39, 40].

thory against experiments, with a model of magma flow in the conduit during Plinian eruptions $[41,4,42]$. We find that the vast majority of eruptions require heterogeneous nucleation, perhaps due to the presence of magnetite crystals. This is consistent with Shea's hypothesis [11]. We assess the implications of heterogeneous bubble nucleation on the conduit flow, with a focus on magma decompression rates. Conduit flow models indicate that decompression rate during magma ascent is not constant. Rather it increases as $\mathrm{H}_{2} \mathrm{O}$ exsolves and viscosity increases [6,43]. Our model simulations account for this time-dependent magma decompression and is more consistent with the fluid dynamics of magma ascent. This allows for the estimation of a time-averaged decompression rate, defined as the ratio of total decompression over total ascent time. The time-averaged decompression rate is well suited for comparison with independent geospeedometers, which yield decompression-rate estimates within close range of the time-averaged values [44]. In contrast, estimates based on scaling relations, such as BND-meter of Toramaru [35] which is widely used [e.g., 11], yields values that are more representative of decompression rates at the peak of nucleation [11], which can be orders of magnitude higher than time-averaged estimates. By accounting for the aforementioned time-dependent feedback during magma decompression, we find that the time-averaged decompression rates estimated from BND under heterogeneous nucleation are consistent with independent geospeedometers.

\section{Results}

\subsection{Bubble nucleation}

Bubble nucleation is the formation of molecular clusters larger than a critical size and stable to grow into bubbles. Nucleation is driven by thermodynamic disequilibrium, due to supersaturation of dissolved volatiles, as magma decompresses to a pressure below its saturation pressure. The change in free energy, $W$, associated with formation of bubble nuclei is quantified by classical nucleation theory [45]. $W$ derives from the balance between a reduction in free energy, caused by the clustering of volatile molecules, and an increase in free energy, caused by the formation of a new interface between molecules within the cluster and the surrounding silicate. The bubble nucleation rate depends exponentially on $W$ [45]. Bubble nuclei are of the order of a few nanometers in size [30,45] and will grow into micronto millimeter-size bubbles by diffusion, which tends to reduce supersaturation.

We simulate bubble nucleation and growth during magma decompression in order to examine the conditions under which bubbles in Plinian pyroclasts may have nucleated (see Methods for details). We consider $\mathrm{H}_{2} \mathrm{O}$ as the dominant volatile phase because it is the most abundant [5] and primarily controls the final bubble number density [4]. Our simulations predict nucleation rate during decompression from an initial saturation 
pressure until magma fragmentation. Decompression rate is estimated for steady flow of magma within a cylindrical conduit of constant cross-sectional area using the Darcy-Weisbach relation [6]. Dependent parameters are: pressure in the surrounding melt, average concentration of dissolved $\mathrm{H}_{2} \mathrm{O}$ in the melt, nucleation rate, bubble number density, average bubble size, pressure inside bubbles, and bubble volume fraction. We use the nucleation model of Hajimirza et al. [30], which has been calibrated against homogeneous bubble nucleation experiments in rhyolite, and reliably predicts experimental results over a wide range of saturation pressures and decompression rates.

The homogeneous nucleation energy, $W_{\mathrm{Hom}}$, is large and a high supersaturation pressure is required to overcome the surface energy barrier for nucleus formation [30, 10]. In our simulations we first examined whether the observed bubble number density in each eruption can be produced by homogeneous nucleation. We find that the 1991 eruption of Pinatubo is the only eruption where the observed bubble number density can be attained by homogeneous nucleation. For all other eruptions studied a necessary reduction in nucleation energy, relative to the homogeneous value, is required. This reduction can be attained by the presence of dissolved fluorine. For example, $1 \mathrm{wt} \%$ fluorine reduces nucleation energy by $75 \%[27]$. Typical fluorine concentrations in explosively erupted magmas, however, are only 200-1500 ppm [5]. An alternative is heterogeneous nucleation on crystals [45], including nanometer-size nanolites [11]. Here we assess the effect of heterogeneous nucleation on magma ascent dynamics during Plinian eruptions.

\subsection{Reconciling bubble nucleation with eruption dynamics}

Heterogeneous nucleation in magmatic systems is facilitated by the presence of crystalline molecular aggregates that provide nucleation sites for bubbles. Heterogeneous nucleation facilitates nucleation by reducing the homogeneous nucleation energy by a factor, $0<\alpha \leq 1$. The value of $\alpha$ during such heterogeneous nucleation is described as a function of the dihedral contact angle, $\theta$, between the melt-bubble interface and the pre-existing crystal (Figure 2). Direct measurements of $\theta$ for bubble nuclei are impossible because nuclei are too small and ephemeral. Some studies have attempted to estimate $\theta$ from the contact angle between microscopically observed bubbles and crystals [46]. It is, however, unlikely that the contact angle is the same for nuclei and microscopically observable bubbles because their thermodynamic properties are different $[30,45]$. Instead, $\theta$ has been inferred from the difference in pressure, $\Delta P$, at which bubbles first nucleate during decompression in homogeneous and heterogeneous nucleation experiments with $\alpha=\left(\Delta P_{\mathrm{Het}} / \Delta P_{\mathrm{Hom}}\right)^{2}$ $[45,47]$. Based on such experiments it has been shown that the contact angle is dependent on the substrate's mineralogical structure (Figure 2). For example, the contact angle for feldspar is approximately $0-20^{\circ}$ [46], for pyroxene it is $40-60^{\circ}$ [48], whereas for hematite it is approximately $90^{\circ}-100^{\circ}[49,47]$, and for magnetite it is approximately $145^{\circ}-160^{\circ}[46,47]$. The contact angles for feldspar and pyroxene are too low to allow heterogeneous nucleation to match the observed bubble number densities (Figure 2). Nucleation on hematite can match observed bubble number densities in most eruptions. To the best of our knowledge, however, hematite does not occur naturally in most magmas. Magnetite is the most effective mineral phase for heterogeneous bubble nucleation and is the only mineral phase

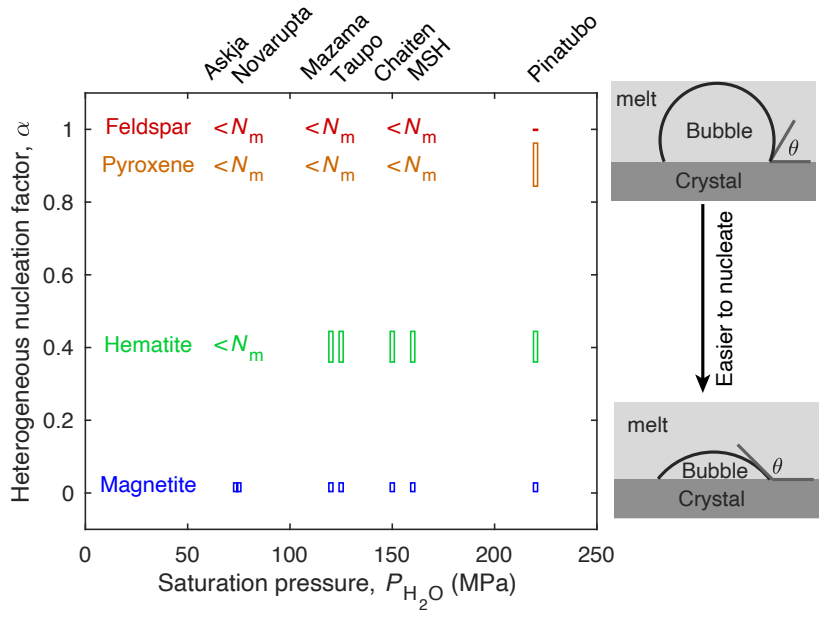

Figure 2: Heterogeneous nucleation on magnetite reconciles $\mathrm{H}_{2} \mathrm{O}$ saturation pressure with bubble number densities. Heterogeneous nucleation factor, $\alpha$, required for each eruption to match bubble number densities. Pinatubo can be reconciled with homogeneous nucleation $(\alpha=1)$, whereas all other eruptions require heterogeneous nucleation $(\alpha<1) . \alpha$ shown are for magnetite [47, 46], hematite [47, 49], pyroxene [48] and feldspar [46]. Magnetite is the only mineral phase that allows heterogeneous nucleation to simultaneously match observed bubble number densities in all eruptions.

that can cause heterogeneous nucleation to produce bubbles in sufficient numbers in all eruptions considered.

For each eruption we ran simulations wherein homogeneous nucleation energy is scaled with $\alpha$ for the range of possible contact angles for magnetite $\left(145^{\circ}-160^{\circ}\right)$. The simulation parameters are given in Supplementary Table 1. The time-averaged decompression rates, at which the magma would be predicted to fragment with a bubble number density equal to each eruption, ranges between $0.1 \mathrm{MPa} / \mathrm{s}$ and $1 \mathrm{MPa} / \mathrm{s}$ (Figure 3). These estimates reconcile observed bubble number densities with nucleation theory and the fundamental fluid dynamics of magma ascent [6]. The time-averaged decompression rates are more than an order of magnitude lower than equivalent values predicted for heterogeneous nucleation by the BND-meter [35]. The reason for this discrepancy is because decompression rates from the BND-meter are representative of peak rates. This is an important distinction because independent geospeedometers, which tend to be based on diffusion kinetics, provide estimates that closely approximate time-averaged values [44]. Thus, the time-averaged decompression rates obtained from our simulations largely eliminate the gap with independent geospeedometers (Figure 3). Despite heterogeneous nucleation generating sufficient numbers of bubbles at slower, more realistic decompression rates, those rates still exceed some estimated from other geospeedometers, which we speculate to be indicative of a widening conduit with depth.

\section{Discussion}

Our simulation results suggest that bubble number densities can be reconciled with pre-eruptive $\mathrm{H}_{2} \mathrm{O}$ concentration and inde- 


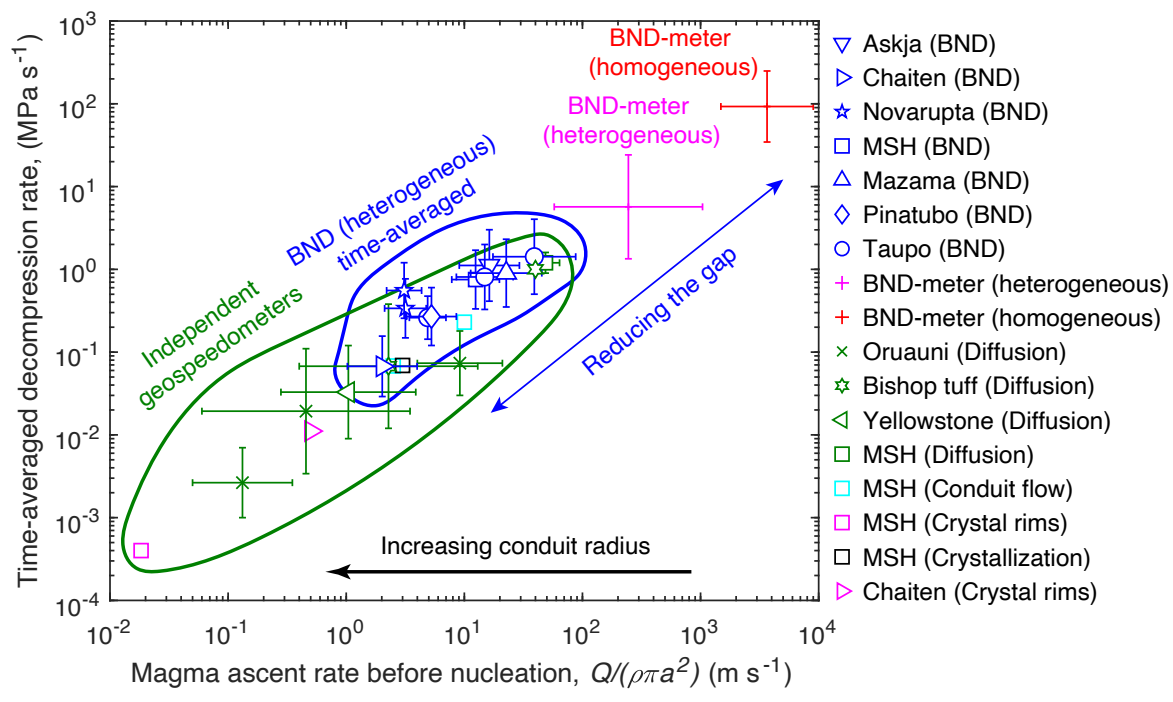

Figure 3: Estimated decompression rates for silicic Plinian eruptions. The blue symbols show the time-averaged estimates from bubble number density with heterogeneous nucleation on magnetite. The errorbars represent uncertainties in magnetite contact angle. Heterogeneous nucleation substantially reduces the gap in decompression rate between homogeneous nucleation and independent geospeedometers that include: diffusion in melt inclusions and melt embayments for May 18th, 1980 Mt. St. Helens [36], 0.77Ma Bishop tuff [50, 51], 27ka Oruauni [52, 53, 51], and 2 Ma Yellowstone [51]; conduit models for May 18th, 1980 Mt. St. Helens [37, 38]; crystal rims for May 18th, 1980 Mt. St. Helens [39] and 2008 Chaiten [15]; and groundmass crystallization for May 18th, 1980 Mt. St. Helens [40].

pendent geospeedometers if nucleation is heterogeneous due to magnetite. For none of the eruptions magnetite crystals have been reported at number densities similar to or greater than bubble number densities. This does not, however, rule out the presence of magnetite because they are typically much smaller than bubbles and might be under-counted in 2D scanning electron microscopy (SEM) images [11, 54]. Furthermore, magnetite crystals might exist at sizes well below the resolution of SEM images. For example, Schlinger et al. [55] reported magnetite nanolites as small as $20 \mathrm{~nm}$ in samples from Paintbrush Tuff (USA), whereas Di Genova et al. [56,57] documented magnetite nanolites in samples from Green Tuff (Italy) and Yellowstone (USA) using Raman spectroscopy. Using transmission electron microscopy Mujin et al. [54] observed magnetite nanolites in samples from Shinmoedake Volcano (Japan) with sizes down to $1 \mathrm{~nm}$ and number densities of up to $\sim 10^{23} \mathrm{~m}^{-3}$.

Our analysis is based on the hypothesis that heterogeneous nucleation sites exist during eruptive magma ascent. This is supported by the fact that bubble nucleation experiments require extensive treatment at superliquidus conditions in order to avoid heterogeneous nucleation, in some cases without observable crystals $[46,58]$. The hypothesized existence of abundant oxides in erupting magmas at subliquidus conditions is thus not unreasonable [11]. By the same token, homogeneous bubble nucleation experiments, while necessary as a basis for understanding nucleation, may not fully encapsulate bubble formation in volcanic eruptions.

Heterogeneous nucleation exerts a complex feedback between $\mathrm{H}_{2} \mathrm{O}$ exsolution, decompression rate, and explosive magma fragmentation. Figure 4 provides a representative example of model results. Heterogeneous nucleation starts shortly after magma decompresses to below the saturation pressure. After the onset of nucleation $\mathrm{H}_{2} \mathrm{O}$ diffuses into the existing bubbles. Bubbles grow, resulting in progressive decrease of the characteristic diffusion length, which enhances the diffusion of $\mathrm{H}_{2} \mathrm{O}$ into bubbles. The average dissolved $\mathrm{H}_{2} \mathrm{O}$ concentration therefore remains close to equilibrium as the magma continues to decompress. The initial decompression rate is predominantly due to the reduction in hydrostatic pressure, which is proportional to magma ascent rate. As more $\mathrm{H}_{2} \mathrm{O}$ exsolves magma viscosity increases and results in a continuous increase in decompression rate. Consequently supersaturation gradually increases, resulting in a second nucleation peak of higher rate than the first one. Because of the substantial overpressure in the newly nucleated bubbles, fragmentation conditions are reached immediately after the second nucleation peak. Our simulations predict that under heterogeneous nucleation a second nucleation peak occurs for all eruptions, independent of their saturation pressure. The detailed simulation results for all eruptions are given in Supplementary Table 2.

In summary, we find that bubbles at number densities in pyroclastic samples from a wide range of Plinian silicic eruptions are consistent with heterogeneous nucleation due to magnetite, if present at number densities similar to those discovered in several explosive eruptions [54, 55, 56, 57]. Such heterogeneous bubble nucleation can resolve the discrepancy between the inferred water saturation for many eruptions and that required to nucleate bubbles. By accounting for the time-varying decompression rate, arising due to feedbacks between $\mathrm{H}_{2} \mathrm{O}$ exsolution and magma viscosity, we overcome the peak decompression-rate bias of conventional methods. We thus calculate time-averaged decompression rates that can be compared to independent geospeedometers. We find that heterogeneous nucleation largely closes the gap with independent geospeedometers. Heterogeneous bubble nucleation due to magnetite is a viable hypothesis that provides im- 


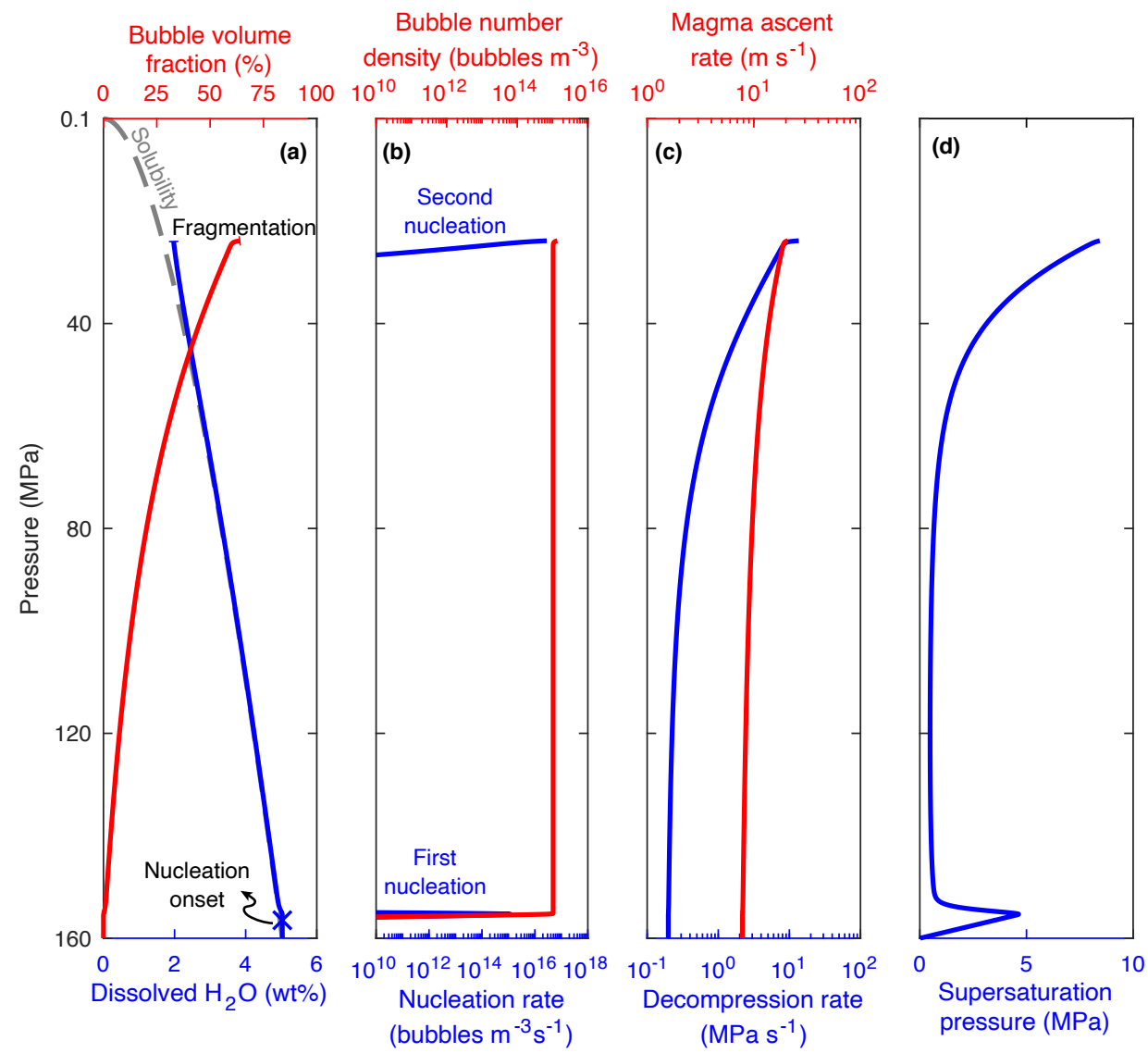

Figure 4: Illustrative model results of the feedback between water exsolution, decompression rate, and magma fragmentation during heterogeneous nucleation. The contact angle is $\theta=160^{\circ}(\alpha=0.003)$. Nucleation first occurs at low supersaturation. Subsequently $\mathrm{H}_{2} \mathrm{O}$ concentration remains close to equilibrium because of $\mathrm{H}_{2} \mathrm{O}$ diffusion into nucleated bubbles. This results in a progressive increase in viscosity and, hence, decompression rate. Supersaturation pressure increases gradually, leading to a second nucleation peak, followed by magma fragmentation.

petus for future investigations, in particular, a systematic search for the presence of magnetite nanolites in Plinian samples.

\section{Methods}

\subsection{Model assumptions}

We simulated bubble nucleation and growth during magma ascent in a vertical cylindrical conduit with a constant cross-sectional area. For a given eruption, simulations commence from $\mathrm{H}_{2} \mathrm{O}$ saturation pressure and stop when fragmentation conditions are met.

The assumption for magma flow in the conduit are: steady state because the time scale for Plinian eruptions is substantially longer than the time scale of magma ascent in the conduit [59]; one-dimensional flow with flow properties averaged over the cross-sectional area of the conduit [6]; the relative velocity between bubbles and melt is neglected because the drag force associated with silicic melt prevents bubbles from rising independently through the melt [43]; isothermal conditions and nucleation is only driven by decompression [42]; nanolites do not affect magma rheology; nucleation after fragmentation is assumed to be negligible [42].

The assumptions for bubble nucleation and growth are: magma is initially bubble free; $\mathrm{H}_{2} \mathrm{O}$ exsolution is non-equilibrium; bubble nucle- ation rate is estimated using classical nucleation theory; nucleation is heterogeneous on abundant pre-existing magnetite crystals (no crystal nucleation); we assume bubble growth is steady state [4]. This is justified because the inertia terms in volatiles diffusion equation are negligible at low supersaturation pressures in heterogeneous nucleation [60]; we use method of moments to estimate the growth rate of bubbles with different sizes. [4].

\subsection{Magma flow in the conduit}

Considering the above assumptions, conservation of mass and momentum simplifies to

$$
\frac{\partial(\rho U)}{\partial z}=0
$$

and

$$
\rho U \frac{\partial U}{\partial z}=-\frac{\partial P_{\mathrm{m}}}{\partial z}-\rho g-F_{\text {fric }},
$$

respectively. Here $\rho$ is magma density, averaged over melt and gas phases,

$$
\rho=\phi \rho_{\mathrm{g}}+(1-\phi) \rho_{\mathrm{m}} .
$$

$\phi$ is the volume fraction of bubbles, $\rho_{\mathrm{g}}$ and $\rho_{\mathrm{m}}$ are gas and melt densities respectively, $U$ is magma ascent rate, $g$ is the gravitational acceleration, and $F_{\text {fric }}$ is the friction force. The latter is calculated from the 
Darcy-Weisbach relation, $F=8 \mu U / a^{2}$. $a$ is the conduit radius, and $\mu$ is the magma viscosity, given by $\mu_{\mathrm{m}}\left(1-\phi_{\text {crystal }} / 0.6\right)^{(-5 / 2)}$. Here $\mu_{\mathrm{m}}$ is the melt viscosity and $\phi_{\text {crystal }}$ is the volume fraction of microlites Substituting equation 1 into equation 2, and replacing $U$ with $Q /\left(\rho \pi a^{2}\right)$ gives decompression rate as

$$
\frac{\partial P_{\mathrm{m}}}{\partial z}=-\left(\rho g+\frac{Q}{\rho \pi a^{2}}\left(\frac{8 \mu}{a^{2}}-\frac{Q}{\rho \pi a^{2}} \frac{\partial \rho}{\partial z}\right)\right),
$$

where $Q$ is the mass discharge rate.

\subsection{Bubble nucleation}

In our model, we allow for non-equilibrium exsolution, that is $\mathrm{H}_{2} \mathrm{O}$ may become supersaturated as magma decompresses, driving bubble nucleation and growth. We used classical nucleation theory to estimate nucleation rate of stable bubble nuclei at a given supersaturation pressure. Molecular clusters of volatiles are stable and grow into bubbles if they are larger than the critical nucleus size, $R_{\mathrm{c}}$, given by [45]

$$
R_{\mathrm{c}}=\frac{2 \gamma}{P_{\mathrm{n}}-P_{\mathrm{m}}}
$$

where $\gamma$ is the surface tension of bubble nuclei, $P_{\mathrm{n}}$ is the pressure inside a bubble nucleus, and $P_{\mathrm{m}}$ is pressure in the surrounding melt. $P_{\mathrm{n}}$ is related to the saturation pressure of volatiles, $P_{\text {sat }}$, through [49]

$$
f\left(P_{\mathrm{n}}, T\right) P_{\mathrm{n}}=f\left(P_{\mathrm{sat}}, T\right) P_{\mathrm{sat}} e^{\Omega\left(P_{\mathrm{m}}-P_{\mathrm{sat}}\right) / k_{\mathrm{B}} T},
$$

where $T$ is temperature, $f(P, T)$ is the fugacity coefficient of the supersaturated volatile phase, $\Omega$ is the volume of volatile molecules, and $k_{\mathrm{B}}$ is the Boltzmann constant. The homogeneous nucleation energy, $W_{\mathrm{Hom}}$ is estimated from

$$
W_{\text {Hom }}=\frac{16 \pi \gamma^{3}}{3\left(P_{\mathrm{n}}-P_{\mathrm{m}}\right)^{2}},
$$

and the nucleation rate is $[61,45]$

$$
J=J_{0} \exp \left(-\frac{W_{\text {Hom }}}{k_{\mathrm{B}} T} \alpha\right)
$$

with

$$
J_{0}=\frac{2 \Omega n_{0}^{2} D}{a_{0}} \sqrt{\frac{\gamma}{k_{\mathrm{B}} T}} .
$$

$n_{0}$ is the concentration of volatiles molecules in the melt, $D$ is the diffusion coefficient, $a_{0}$ is the average distance between volatiles molecules. and $\alpha$ is the nucleation factor. Here we use the heterogeneous nucleation factor, $\alpha$, which depends on the contact angle, $\theta$, between bubble nuclei and crystals as

$$
\alpha=\frac{(2-\cos \theta)(1+\cos \theta)^{2}}{4} .
$$

The nucleation rate is strongly controlled by surface tension, $\gamma$, such that a few percent variations in $\gamma$ can change $J$ by $>10$ orders of magnitude [32]. A reliable prediction of nucleation rate, and consequently bubble number density, thus requires a firm constraint on surface tension. Here we use the surface tension formulation defined by Hajimirza et al. [30], which has been shown to reliably predict observed bubble number density in homogeneous nucleation experiments . $\gamma$ is given by

$$
\gamma=\frac{0.49 \gamma_{\mathrm{B}}}{1+2 \delta / R_{\mathrm{c}}}
$$

where $\gamma_{\mathrm{B}}$ is the surface tension measurements for macroscopic bubbles [62], and $\delta \approx 0.32 \mathrm{~nm}$ is the Tolman length for bubble nuclei in rhyolite $[30,63]$.

\subsection{Bubble growth}

When a bubble nucleus forms, the $\mathrm{H}_{2} \mathrm{O}$ concentration at the bubble-melt interface is determined by the solubility of $\mathrm{H}_{2} \mathrm{O}$ at the pressure inside the bubble. This concentration is lower than the concentration in the surrounding melt, resulting in a concentration gradient which drives diffusion of $\mathrm{H}_{2} \mathrm{O}$ molecules toward bubble nuclei. The resultant mass flux of $\mathrm{H}_{2} \mathrm{O}$ into a bubble, $q$, is approximated as,

$$
q=D\left(\frac{\partial c}{\partial r}\right)_{r=R} .
$$

Here $D$ is diffusion coefficient, $r$ is the distance from bubble's center, $R$ is bubble radius, and $c$ is the water concentration in the surrounding melt, given by [7]

$$
\frac{\partial c}{\partial t}+\frac{d R}{d t} \frac{\partial c}{\partial z}=\frac{1}{r^{2}} \frac{\partial c}{\partial r}\left(D r^{2} \frac{\partial c}{\partial r}\right) .
$$

Chernov et al. [60] demonstrated that at low supersaturation pressures the inertial terms, the left hand side in equation (13), are negligible. We thus neglect those terms because in heterogeneous nucleation $\mathrm{H}_{2} \mathrm{O}$ is expected to remain near equilibrium. With boundary conditions $c(r=R)=C_{\mathrm{R}}$ and $c(r \rightarrow \infty)=C_{\mathrm{m}}$, where $C_{\mathrm{m}}$ and $C_{\mathrm{R}}$ are the average $\mathrm{H}_{2} \mathrm{O}$ concentrations in the melt and at the bubble-melt interface, respectively, $c$ is estimated as [60]

$$
c=C_{\mathrm{m}}-\left(C_{\mathrm{m}}-C_{\mathrm{R}}\right) \frac{R}{r} .
$$

The mass of $\mathrm{H}_{2} \mathrm{O}$ inside the bubble, $m_{\mathrm{b}}$, will increase due to diffusion at a rate

$$
\frac{d m_{\mathrm{b}}}{d t}=4 \pi R^{2} \rho_{\mathrm{m}} q .
$$

Bubble growth rate is given by

$$
\frac{d R}{d t}=\frac{R}{4 \mu}\left(P_{\mathrm{b}}-P_{\mathrm{m}}-\frac{2 \gamma}{R}\right),
$$

which accounts for bubble growth driven by diffusion as well as decompression. Here $\mu$ is the viscosity of melt surrounding the bubble, $P_{\mathrm{b}}$ is the pressure inside the bubble, estimated using the equation of state of $\mathrm{H}_{2} \mathrm{O}$, and $d / d t=U \partial / \partial z$ is the material derivatives of a given quantity in steady state. Inertial terms in equation 16 are neglected, given that they are considerably smaller than the viscous terms [4].

The above equations describe the growth rate of a single bubble. Because the number of bubbles in the magma are too high to track growth rates for each individual bubble, we use the method of moments, which calculates the moments of size distributions. The $k$ th moment is defined as [4]

$$
M_{k}(t)=\int_{0}^{\infty} R^{k} \Lambda(R, t) d R,
$$

where $\Lambda$ is number of bubbles with radii in the interval of $R$ and $R+$ $d R$ per unit volume of melt. Each moment refers to a measurable characteristic quantity [4]: $M_{0}$ is the total number of bubbles per unit volume of melt (BND), $M_{1}$ is the total radius of bubbles per unit volume of melt, $4 \pi M_{2}$ is the total surface area of bubbles per unit volume of melt and $\frac{4 \pi}{3} M_{3}$ is the total volume of bubbles per unit volume of melt. The volume fraction of bubbles in equation (3) is estimated from $\left(\frac{4 \pi}{3} M_{3}\right) /\left(1+\frac{4 \pi}{3} M_{3}\right)$.

Each moment varies through time because of evolution of bubble size distribution due to the growth of existing bubbles and nucleation of new bubbles. The population balance equation is given by [41]

$$
\frac{d \Lambda(R, t)}{d t}+G(\hat{R}) \frac{\partial(\Lambda(R, t))}{\partial R}=J \int_{0}^{\infty} \delta\left(R-R_{\mathrm{c}}\right) d R .
$$

$\delta$ is the Dirac delta function and $G(\hat{R})$ is the growth rate of bubbles, assumed to be equal for all bubbles and estimated from equation (16) 
for a bubble with the size equivalent to mean bubble radius, $\hat{R}=M_{1} / M_{0}$. The evolution of the zeroth moment through time is given by

$$
\frac{d M_{0}}{d t}=J
$$

and the evolution of the higher order moments, $\mathrm{k} \geq 1$ is given by

$$
\frac{d M_{k}}{d t}=k G(\hat{R}) M_{k-1}+J R_{\mathrm{c}}^{k}
$$

The concentration of $\mathrm{H}_{2} \mathrm{O}$ dissolved within the melt decreases as a result of the diffusion of water into bubbles. Mass conservation of $\mathrm{H}_{2} \mathrm{O}$ requires that

$$
\frac{d C_{\mathrm{m}}}{d t}=-\frac{1}{\rho_{m}}\left(M_{0} \frac{d m_{\mathrm{b}}}{d t}+J m_{\mathrm{c}}\right),
$$

where $\rho_{\mathrm{m}}$ is the melt density, assumed to be constant throughout magma decompression, and $m_{\mathrm{c}}$ is the mass of a bubble nuclei estimated from equation of state.

\subsection{Model simulation}

For each eruption we integrated equations 4, 19, 20 for $k=1$ through 3 , as well as equations 21 using the ode15s function of MATLAB ${ }^{\circledR}$ Each simulation initiated at the known saturation pressure and with additional initial conditions of

$$
M_{k}=0, \quad P_{\mathrm{m}}=P_{\mathrm{H}_{2} \mathrm{O}} \text { and } C_{\mathrm{m}}=C_{\mathrm{H}_{2} \mathrm{O}},
$$

where $C_{\mathrm{H}_{2} \mathrm{O}}$ is related to $P_{\mathrm{H}_{2} \mathrm{O}}$ through the $\mathrm{H}_{2} \mathrm{O}$ solubility relation [64]. A given simulation ends when the fragmentation criterion of Papale [65] is reached. The values of input variables for each eruption are given in Supplementary Table 1.

The objective of our model simulation is to estimate decompression rate, conditional on the observational constraints of measured bubble number density and magma fragmentating. All parameters in the governing system of equations are either specified or calculated from existing formulations: $\mathrm{H}_{2} \mathrm{O}$ solubility [64], diffusion coefficient [66], equation of state [67], fugacity coefficient [67], surface tension [30], melt viscosity [9], and the molecular volume of $\mathrm{H}_{2} \mathrm{O}$ [68]. Conduit radius, which is related to decompression rate through equation 4 , is the only parameter that is not constrained. For each eruption, the model simulations predict a conduit radius and an average decompression rate that are conditional on the aforementioned observational constraints. The values of output variables for each eruption is given in Supplementary Table 2.

\section{ACKNOWLEDGEMENTS}

This work was supported by the National Science Foundation grants EAR-1348072 and EAR-1348050. We thank Mattia de' Michieli Vitturi, Michihiko Nakamura, and one anonymous reviewer for their valuable suggestions and comments.

\section{AUTHOR CONTRIBUTION}

S.H. carried out the numerical simulations. S.H., H.M.G., and J.E.G participated in interpretations of the results and preparation of the manuscript.

\section{DATA AVAILABILITY}

The authors declare that the data that support the findings of this study are available within the paper and the supplementary tables.

\section{Code availability}

All equations used in the code are presented in the Methods section. The code is available at "https://github.com/Sahand-Hajimirza/BNDspeedometer".

\section{COMPETING INTERESTS}

The authors declare no competing interests.

\section{REFERENCES}

[1] S. Carey and H. Sigurdsson. The intensity of plinian eruptions. Bulletin of Volcanology, 51:28-40, 1989. doi: 10.1007/BF01086759.

[2] H. S. Crosweller, B. Arora, S. K. Brown, E. Cottrell, N. I. Deligne, N. O. Guerrero, L. Hobbs, K. Kiyosugi, S. C. Loughlin, J. Lowndes, M. Nayembil, L. Siebert, R. S. J. Sparks, S. Takarada, and E. Venzke. Global database on large magnitude explosive volcanic eruptions (LaMEVE). Journal of Applied Volcanology, 1:1-13, 2012. doi: 10. 1186/2191-5040-1-4.

[3] R. Stephen J. Sparks. The dynamics of bubble formation and growth in magmas: A review and analysis. Journal of Volcanology and Geothermal Research, 3(1-2):1-37, mar 1978. ISSN 03770273. doi: 10.1016/0377-0273(78) 90002-1.

[4] A. Toramaru. Numerical study of nucleation and growth of bubbles in viscous magmas. Journal of Geophysical Research: Solid Earth, 100:1913-1931, 1995. doi: 10. 1029/94JB02775.

[5] P. J. Wallace, T. Plank, M. Edmonds, and E. H. Hauri. Chapter 7 - volatiles in magmas. In H. Sigurdsson, B. Houghton, S. McNutt, R. Hazel, and J. Stix, editors, The Encyclopedia of Volcanoes (Second Edition), pages 163 - 183. Academic Press, Amsterdam, 2015. doi: 10.1016/B978-0-12-385938-9.00007-9.

[6] L. Wilson, R. S. J. Sparks, and G. P. L. Walker. Explosive volcanic eruptions - IV. The control of magma properties and conduit geometry on eruption column behaviour. Geophysical Journal International, 63:117-148, 1980. doi: 10.1111/j.1365-246X.1980.tb02613.x.

[7] H. M. Gonnermann and M. Manga. Dynamics of magma ascent. In S. A. Fagents, T. K. P. Gregg, and M. C. Lopes, editors, Modeling volcanic processes: The physics and mathematics of volcanism, pages 55-84. Cambridge University Press, Cambridge, UK, 2013.

[8] M. Cassidy, M. Manga, K. V. Cashman, and O. Bachmann. Controls on explosive-effusive volcanic eruption styles. Nature Communications, 9:2839, 2018.

[9] H. Hui and Y. Zhang. Toward a general viscosity equation for natural anhydrous and hydrous silicate melts. Geochimica et Cosmochimica Acta, 71:403-416, 2007. doi: 10.1016/j.gca.2006.09.003.

[10] M. T. Mangan and T. Sisson. Delayed, disequilibrium degassing in rhyolite magma: decompression experiments and implications for explosive volcanism. Earth and Planetary Science Letters, 183:441-455, 2000. doi: 10.1016/S0012-821X(00)00299-5. 
[11] T. Shea. Bubble nucleation in magmas: A dominantly heterogeneous process? Journal of Volcanology and Geothermal Research, 343:155-170, 2017. doi: 10.1016/j. jvolgeores.2017.06.025.

[12] R. J. Carey, B. F. Houghton, and T. Thordarson. Abrupt shifts between wet and dry phases of the 1875 eruption of Askja Volcano: Microscopic evidence for macroscopic dynamics. Journal of Volcanology and Geothermal Research, 184:256-270, 2009. doi: 10.1016/j.jvolgeores.2009.04. 003.

[13] H. Sigurdsson and R. S. J. Sparks. Petrology of Rhyolitic and Mixed Magma Ejecta from the 1875 Eruption of Askja, Iceland. Journal of Petrology, 22:41-84, 1981. doi: 10. 1093/petrology/22.1.41.

[14] F. Alfano, C. Bonadonna, and L. Gurioli. Insights into eruption dynamics from textural analysis: the case of the May, 2008, Chaitén eruption. Bulletin of Volcanology, 74: 2095-2108, 2012. doi: 10.1007/s00445-012-0648-3.

[15] J. M. Castro and D. B. Dingwell. Rapid ascent of rhyolitic magma at Chaitén Volcano, Chile. Nature, 461:780-783, 2009. doi: 10.1038/nature08458.

[16] C. Klug, K. V. Cashman, and C. Bacon. Structure and physical characteristics of pumice from the climactic eruption of Mount Mazama (Crater Lake), Oregon. Bulletin of Volcanology, 64:486-501, 2002. doi: 10.1007/ s00445-002-0230-5.

[17] C. R. Bacon and T. H. Druitt. Compositional evolution of the zoned calcalkaline magma chamber of Mount Mazama, Crater Lake, Oregon. Contributions to Mineralogy and Petrology, 98:224-256, 1988. doi: 10.1007/BF00402114.

[18] S. Carey, H. Sigurdsson, J. E. Gardner, and W. Cristwell Variations in column height and chamber during the May 18, 1980 eruption of Mt. St. Helens. Journal of Volcanology and Geothermal Research, 43:99-112, 1990. doi: 10.1016/0377-0273(90)90047-J.

[19] M. J. Rutherford, H. Sigurdsson, S. Carey, and A. Davis The May 18, 1980, eruption of Mount St. Helens. 1. Melt composition and experimental phase equilibria. Journal of Geophysical Research, 90:2929-2947, 1985. doi: 10. 1029/JB090iB04p02929.

[20] C. Klug and K. V. Cashman. Vesiculation of May 18, 1980 , Mount St. Helens magma. Geology, 22:468, 1994. doi: 10. 1130/0091-7613(1994)022<0468:VOMMSH>2.3.CO;2.

[21] N. K. Adams, B. F. Houghton, and W. Hildreth. Abrupt transitions during sustained explosive eruptions: examples from the 1912 eruption of Novarupta, Alaska. Bulletin of Volcanology, 69:189-206, 2006. doi: 10.1007/ s00445-006-0067-4.

[22] J. E. Hammer, M. J. Rutherford, and W. Hildreth. Magma storage prior to the 1912 eruption at Novarupta, Alaska. Contributions to Mineralogy and Petrology, 144:144-162, 2002. doi: 10.1007/s00410-002-0393-2.

[23] M. Polacci, P. Papale, and M. Rosi. Textural heterogeneities in pumices from the climactic eruption of Mount Pinatubo, 15 June 1991, and implications for magma ascent dynamics. Bulletin of Volcanology, 63:83-97, 2001. doi: 10.1007/s004450000123.
[24] J. E. Hammer and M. J. Rutherford. An experimental study of the kinetics of decompression-induced crystallization in silicic melt. Journal of Geophysical Research: Solid Earth, 107:ECV 8-1-ECV 8-24, 2002. doi: 10.1029/ $2001 \mathrm{jb} 000281$.

[25] B. F. Houghton, R. J. Carey, K. V. Cashman, C. J. N. Wilson, B. J. Hobden, and J. E. Hammer. Diverse patterns of ascent, degassing, and eruption of rhyolite magma during the $1.8 \mathrm{ka}$ Taupo eruption, New Zealand: Evidence from clast vesicularity. Journal of Volcanology and Geothermal Research, 195:31-47, 2010. doi: 10.1016/j.jvolgeores.2010.06.002.

[26] J. E. Gardner and R. A. Ketcham. Bubble nucleation in rhyolite and dacite melts: Temperature dependence of surface tension. Contributions to Mineralogy and Petrology, 162:929-943, 2011. doi: 10.1007/s00410-011-0632-5.

[27] J. E. Gardner, S. Hajimirza, J. D. Webster, and H. M. Gonnermann. The impact of dissolved fluorine on bubble nucleation in hydrous rhyolite melts. Geochimica et Cosmochimica Acta, 226:174-181, 2018. doi: 10.1016/j.gca. 2018.02.013.

[28] H. M. Gonnermann and J. E. Gardner. Homogeneous bubble nucleation in rhyolitic melt: Experiments and nonclassical theory. Geochemistry, Geophysics, Geosystems, 14(11):4758-4773, 2013. doi: 10.1002/ggge.20281.

[29] T. Giachetti, H. M. Gonnermann, J. E. Gardner, A. Burgisser, S. Hajimirza, T. C. Earley, N. Truong, and P. Toledo. Bubble Coalescence and Percolation Threshold in Expanding Rhyolitic Magma. Geochemistry, Geophysics, Geosystems, 20:1054-1074, 2019. doi: 10.1029/2018GC008006.

[30] S. Hajimirza, H. M. Gonnermann, J. E. Gardner, and T. Giachetti. Predicting homogeneous bubble nucleation in rhyolite. Journal of Geophysical Research: Solid Earth, 124:2395-2416, 2019. doi: 10.1029/2018JB015891.

[31] M. Hamada, D. Laporte, N. Cluzel, K. T. Koga, and T. Kawamoto. Simulating bubble number density of rhyolitic pumices from Plinian eruptions: constraints from fast decompression experiments. Bulletin of Volcanology, 72:735-746, 2010. doi: 10.1007/s00445-010-0353-z.

[32] M. T. Mangan and T. Sisson. Evolution of melt-vapor surface tension in silicic volcanic systems: Experiments with hydrous melts. Journal of Geophysical Research, 110: B01202, 2005. doi: 10.1029/2004JB003215.

[33] C. C. Mourtada-Bonnefoi and D. Laporte. Homogeneous bubble nucleation in rhyolitic magmas: An experimental study of the effect of $\mathrm{H} 2 \mathrm{O}$ and $\mathrm{CO} 2$. Journal of Geophysical Research: Solid Earth, 107(B4):ECV 2-1-ECV 2-19, 2002. doi: 10.1029/2001JB000290.

[34] C. C. Mourtada-Bonnefoi and D. Laporte. Kinetics of bubble nucleation in a rhyolitic melt: an experimental study of the effect of ascent rate. Earth and Planetary Science Letters, 218(3-4):521-537, 2004. doi: 10.1016/ S0012-821X(03)00684-8.

[35] A. Toramaru. BND (bubble number density) decompression rate meter for explosive volcanic eruptions. Journal of Volcanology and Geothermal Research, 154:303-316, 2006. doi: 10.1016/j.jvolgeores.2006.03.027. 
[36] M. C. S. Humphreys, T. Menand, J. D. Blundy, and K. Klimm. Magma ascent rates in explosive eruptions: Constraints from $\mathrm{H}_{2} \mathrm{O}$ diffusion in melt inclusions. Earth and Planetary Science Letters, 270:25-40, 2008.

[37] S. Carey and H. Sigurdsson. The May 18, 1980 eruption of Mount St. Helens: 2. Modeling of dynamics of the Plinian phase. Journal of Geophysical Research, 90:2948, 1985. doi: 10.1029/JB090iB04p02948.

[38] P. Papale and F. Dobran. Magma flow along the volcanic conduit during the Plinian and pyroclastic flow phases of the May 18, 1980, Mount St. Helens eruption. Journal of Geophysical Research, 99:4355-4373, 1994. doi: 10. 1029/93JB02972.

[39] M. J. Rutherford and P. M. Hill. Magma ascent rates from amphibole breakdown: An experimental study applied to the 1980-1986 Mount St. Helens Eruptions. Journal of Geophysical Research: Solid Earth, 98:19667-19685, 1993. doi: 10.1029/93JB01613.

[40] C. H. Geschwind and M. J. Rutherford. Crystallization of microlites during magma ascent: the fluid mechanics of 1980-1986 eruptions at Mount St. Helens. Bulletin of Volcanology, 57:356-370, 1995.

[41] Atsushi Toramaru. Measurement of bubble size distributions in vesiculated rocks with implications for quantitative estimation of eruption processes. Journal of Volcanology and Geothermal Research, 43(1-4):71-90, oct 1990. ISSN 03770273. doi: 10.1016/0377-0273(90)90045-H.

[42] H. Massol and T. Koyaguchi. The effect of magma flow on nucleation of gas bubbles in a volcanic conduit. Journal of Volcanology and Geothermal Research, 143:69-88, 2005. doi: 10.1016/j.jvolgeores.2004.09.011.

[43] Larry G. Mastin and Mark S. Ghiorso. A numerical program for steady-state flow of magma-gas mixtures through vertical eruptive conduits. Technical report, Department of the Interior, Washington DC, 2000.

[44] Anna Barth, Megan Newcombe, Terry Plank, Helge M. Gonnermann, Sahand Hajimirza, Gerardo J. Soto, Armando Saballos, and Erik Hauri. Magma decompression rate correlates with explosivity at basaltic volcanoes Constraints from water diffusion in olivine. Journal of Volcanology and Geothermal Research, 387(August):106664, 2019. doi: 10.1016/j.jvolgeores.2019.106664.

[45] O. Navon and V. Lyakhovsky. Vesiculation processes in silicic magmas. In J. S. Gilbert and R. S. J. Sparks, editors, The physics of explosive volcanic eruptions, pages 27-50. Geological Society, London, Special Publications, Cambridge, UK, 1998.

[46] S. Hurwitz and O. Navon. Bubble nucleation in rhyolitic melts: Experiments at high pressure, temperature, and water content. Earth and Planetary Science Letters, 122: 267-280, 1994. doi: 10.1016/0012-821X(94)90001-9.

[47] J. E. Gardner and M. Denis. Heterogeneous bubble nucleation on Fe-Ti oxide crystals in high-silica rhyolitic melts. Geochimica et Cosmochimica Acta, 68:3587-3597, 2004. doi: 10.1016/j.gca.2004.02.021.

[48] Jessica F. Larsen. Heterogeneous bubble nucleation and disequilibrium $\mathrm{H} 2 \mathrm{O}$ exsolution in Vesuvius K-phonolite melts. Journal of Volcanology and Geothermal Research, 175(3):278-288, aug 2008. ISSN 03770273. doi: 10.1016/ j.jvolgeores.2008.03.015.

[49] N. Cluzel, D. Laporte, A. Provost, and I. Kannewischer. Kinetics of heterogeneous bubble nucleation in rhyolitic melts: implications for the number density of bubbles in volcanic conduits and for pumice textures. Contributions to Mineralogy and Petrology, 156:745-763, 2008. doi: 10.1007/s00410-008-0313-1.

[50] A. T. Anderson. Hourglass inclusions: theory and application to the Bishop Rhyolitic Tuff. American Mineralogist, 76(3-4):530-547, 1991. ISSN 0003004X.

[51] Madison L. Myers, Paul J. Wallace, Colin J.N. Wilson, James M. Watkins, and Yang Liu. Ascent rates of rhyolitic magma at the onset of three caldera-forming eruptions. American Mineralogist, 103(6):952-965, 2018. ISSN 19453027. doi: 10.2138/am-2018-6225.

[52] B. L.A. Charlier, D. J. Morgan, C. J.N. Wilson, J. L. Wooden, A. S.R. Allan, and J. A. Baker. Lithium concentration gradients in feldspar and quartz record the final minutes of magma ascent in an explosive supereruption. Earth and Planetary Science Letters, 319-320:218-227, 2012. ISSN 0012821X. doi: 10.1016/j.epsl.2011.12.016.

[53] Yang Liu, Alfred T. Anderson, and Colin J.N. Wilson. Melt pockets in phenocrysts and decompression rates of silicic magmas before fragmentation. Journal of Geophysical Research: Solid Earth, 112(6):1-12, 2007. ISSN 21699356. doi: 10.1029/2006JB004500.

[54] M. Mujin, M. Nakamura, and A. Miyake. Eruption style and crystal size distributions: Crystallization of groundmass nanolites in the 2011 Shinmoedake eruption. American Mineralogist, 102:2367-2380, 2017. doi: 10.2138/am-2017-6052CCBYNCND.

[55] C. M. Schlinger, J. G. Rosenbaum, and D. R. Veblen. Feoxide microcrystals in welded tuff from southern Nevada: Origin of remanence carriers by precipitation in volcanic glass. Geology, 16:556-559, 1988. doi: 10.1130/ 0091-7613(1988)016<0556:FOMIWT>2.3.CO;2.

[56] D. Di Genova, S. Kolzenburg, S. Wiesmaier, E. Dallanave, D. R. Neuville, K. U. Hess, and D. B. Dingwell. A compositional tipping point governing the mobilization and eruption style of rhyolitic magma. Nature, 552:235-238, 2017. doi: $10.1038 /$ nature24488.

[57] D. Di Genova, A. Caracciolo, and S. Kolzenburg. Measuring the degree of "nanotilization" of volcanic glasses: Understanding syn-eruptive processes recorded in melt inclusions. Lithos, 318-319:209-218, 2018. doi: 10.1016/j. lithos.2018.08.011.

[58] J. E. Gardner, M. Hilton, and M. R. Carroll. Experimental constraints on degassing of magma: isothermal bubble growth during continuous decompression from high pressure. Earth and Planetary Science Letters, 168:201-218, 1999. doi: 10.1016/S0012-821X(99)00051-5.

[59] Yu B. Slezin. The mechanism of volcanic eruptions (a steady state approach). Journal of Volcanology and Geothermal Research, 122(1-2):7-50, 2003. ISSN 03770273. doi: 10.1016/S0377-0273(02)00464-X. 
[60] A. A. Chernov, V. K. Kedrinsky, and A. A. Pil'nik. Kinetics of gas bubble nucleation and growth in magmatic melt at its rapid decompression. Physics of Fluids, 26(11), 2014. ISSN 10897666. doi: 10.1063/1.4900846.

[61] J. P. Hirth, G. M. Pound, and G. R. St. Pierre. Bubble nucleation. Metallurgical Transactions, 1(4):939-945, 1969. ISSN 1543-1916. doi: 10.1007/BF02811776.

[62] N. Bagdassarov, A. Dorfman, and D. B. Dingwell. Effect of alkalis, phosphorus, and water on the surface tension of haplogranite melt. American Mineralogist, 85:33-40, 2000. doi: 10.2138/am-2000-0105.

[63] R. C. Tolman. The Effect of Droplet Size on Surface Tension. The Journal of Chemical Physics, 17:333-337, 1949. doi: 10.1063/1.1747247.

[64] Y. Liu, Y. Zhang, and H. Behrens. Solubility of $\mathrm{H}_{2} \mathrm{O}$ in rhyolitic melts at low pressures and a new empirical model for mixed $\mathrm{H}_{2} \mathrm{O}-\mathrm{CO}_{2}$ solubility in rhyolitic melts. Journal of Volcanology and Geothermal Research, 143:219-235, 2005. doi: 10.1016/j.jvolgeores.2004.09.019.

[65] P. Papale. Strain-induced magma fragmentation in explosive eruptions. Nature, 397(February):425-428, 1999. ISSN 0028-0836. doi: 10.1038/17109.

[66] $\mathrm{Y}$. Zhang and $\mathrm{H}$. Behrens. $\mathrm{H}_{2} \mathrm{O}$ diffusion in rhyolitic melts and glasses. Chemical Geology, 169:243-262, 2000. doi: 10.1016/s0009-2541(99)00231-4.

[67] J. R. Holloway. Fugacity and activity of molecular species in supercritical fluids. Springer Netherlands, Dordrecht, Netherlands, 1977. doi: 10.1007/978-94-010-1252-2\@9.

[68] F. A. Ochs and R. A. Lange. The density of hydrous magmatic liquids. Science, 283:1314-1317, 1999. doi: 10.1126/science.283.5406.1314. 